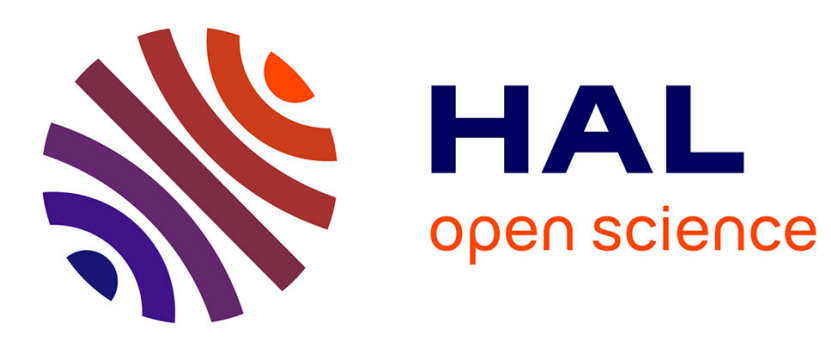

\title{
Prediction of Fracture in the Transition Regime: Application to an A533B Pressure Vessel Steel
}

C. Eripret, D. Lidbury, A. Sherry, I. Howard

\section{To cite this version:}

C. Eripret, D. Lidbury, A. Sherry, I. Howard. Prediction of Fracture in the Transition Regime: Application to an A533B Pressure Vessel Steel. Journal de Physique IV Proceedings, 1996, 06 (C6), pp.C6-315-C6-323. 10.1051/jp4:1996631 . jpa-00254459

\section{HAL Id: jpa-00254459 https://hal.science/jpa-00254459}

Submitted on 1 Jan 1996

HAL is a multi-disciplinary open access archive for the deposit and dissemination of scientific research documents, whether they are published or not. The documents may come from teaching and research institutions in France or abroad, or from public or private research centers.
L'archive ouverte pluridisciplinaire HAL, est destinée au dépôt et à la diffusion de documents scientifiques de niveau recherche, publiés ou non, émanant des établissements d'enseignement et de recherche français ou étrangers, des laboratoires publics ou privés. 


\title{
Prediction of Fracture in the Transition Regime: Application to an A533B Pressure Vessel Steel
}

\author{
C. Eripret, D.P.G. Lidbury*, A. Sherry* and I. Howard** \\ Electricité de France, Research Division, Fracture Mechanics Group, Les Renardières Research Centre, \\ 77250 Moret-sur-Loing, France \\ * AEA Technology, Structural Performance Department, Risley, Warrington, Cheshire WA3 6AT, U.K. \\ ** SIRIUS, University of Sheffield, Department of Mechanical and Process Engineering, Mappin Street, \\ Sheffield, SI 3JD, U.K.
}

\begin{abstract}
In order to model the fracture behaviour of pressure vessel steels in the transition regime, a new model has been developped in 1991 at EDF R\&D Division in the framework of local approach to fracture. This approach couples the damage mechanics model developped by Rousselier which is accounting for ductile propagation of a crack, and the Beremin's model based on Weibull's statistics which stands for cleavage. It is possible to predict, by this coupled approach, safe lower bound transition curves for a temperature range up to RTNDT $+50^{\circ} \mathrm{C}$. It has been shown that the predictions of the model agree well with the experimental data, both in terms of fracture toughness at cleavage instability and the amount of pre-cleavage tearing. Those predicted curves have also been compared to the ASME design curve, and substantial safety margins have been exhibited.
\end{abstract}

\section{INTRODUCTION}

Modelling the fracture behaviour of pressure vessel steels is of major importance for related structural integrity assessments. It is essential to understand how fracture micromechanisms control the transition between ductile tearing and cleavage for preventing unstable fracture. Moreover, it is known that the transition temperature ferritic steels is dependent on geometry effects. Cleavage fracture toughness is affected by size effects, and ductile tearing resistance is influenced by local stress triaxiality. Then, it is necessary to investigate how local stress state, local strains et ductile tearing may affect the so-called critical cleavage fracture stress, which has been commonly considered as an intrinsic property of the material, independent on temperature.

Firstly, the effect of prior stable crack growth on cleavage fracture onset has to be clarified. Prior crack tip blunting or ductile tearing may result in modifying the material resistance to brittle fracture because of prestrain effects. Secondly, the consequences of specimen size effects on both cleavage and ductile tearing must be taken into account : the relative part of ductile crack growth and brittle fracture that can be observed on fracture surfaces depends on thickness of specimens and related volume of the plastic zone, as shown by the statistical model developped by Beremin [1]. More recently, other works [2] also introduced the size effect through the relation : $K_{1 c} B^{1 / 4}=$ constant. Lastly, the validity limits of toughness testing procedures should be accurately defined to include properly the combined effects of ductile crack growth, plasticity development, and possibility to get brittle fracture even after stable crack growth of few millimeters. Some proposals have been made over the last ten years [3][4].

Numerous works have tried to clarify those points by performing tests on A533B or A508 steels, involving toughness tests on different types of specimens from $0.5 \mathrm{~T}$ to $10 \mathrm{~T} C \mathrm{~T}$ or SENB, including fractographic observations, ductile crack growth measurement, identification of cleavage -initiation sites 
and the role played by inclusions ( $\mathrm{MnS}$ for instance), finite element analyses and statistics. Among those attempts, local approach to fracture has been used in order to investigate more precisely the size effects and the scatter of toughness tests results that could be obtained on CT specimens or large-scale pressure vessels. However, it turned out that this approach, i.e. the so-called Weibull statistical model, proved to be able to predict the fracture behaviour of RPV steels in the lower part of the transition regime, but failed in the middle and upper part when an important amount of stable crack growth occurs prior that cleavage takes place.

In order to improve the predictions of those models in the middle part of the transition regime, a new model has been developped in 1991 at EDF R\&D Division in the framework of local approach to fracture [5]. This approach couples the damage mechanics model developped by Rousselier which is accounting for ductile propagation of a crack, and the Beremin's model based on Weibull's statistics which stands for cleavage.

\section{DEVELOPMENT OF THE MODEL}

Local approach to fracture methodology involves failure criteria that are established on the basis of microscopical observations of damage and fracture mechanisms. These criteria are calculated from stresses and strains fields that are computed in the vicinity of cracks or geometrical singularities through finite element analyses. Criteria are determined from microscopical observations of damage and fracture mechanisms (SEM observations on fracture surfaces, on cuts of specimens after interrupted tests, or even on small and thin specimens directly tested in the SEM), compared with the microscopical and macroscopical mechanical fields.

Following those guidelines, the fractographies carried out on CT specimen fracture surfaces have shown, in the transition region, that :

- when cleavage occurs, it leads to unstable and total failure of the specimen. Therefore, we do not consider in this work any pop-in or crack arrest event,

- ductile fracture may occur before cleavage, but not after. No significant zone of ductile tearing exhibiting dimples for instance was observed on the specimens fracture surfaces after that unstable cleavage failure had occured.

The solution that has been adopted consists in coupling two existing models accounting respectively for ductile tearing and cleavage fracture. The first model is the damage model developed by Rousselier [6], which predicts ductile tearing initiation but also simulates crack propagation. The second model, which is accounting for cleavage fracture, is the statistical model developed by Beremin [1]. This model provides the lower and upper bounds of the experimental scatter which is associated with cleavage toughness tests.

\subsection{Presentation of Rousselier damage model}

Many previous works have shown that predictions of the Rousselier damage model for ductile tearing of pressure vessel steels at high temperatures (higher than RTNDT $+100^{\circ} \mathrm{C}$ ) are very accurate [7][8][9] and are relevant for investigating R-curves dependence on specimens geometry or higher toughness properties of large-scaled structures compared to usual laboratory specimens (1T CT for instance). Transferability problems have been solved by using damage models such as Rousselier or Gurson's model, and toughness properties estimations of pressure vessels have even been derived from damage model analysis from simple tensile tests [10]. 
The damage model developed by Rousselier [6], which predicts ductile tearing initiation but also simulates crack propagation by taking into account the softening effects of growing cavities on the weakened mechanical resistance of the damaged material. This model refers to the generalised standard material constitutive relations, and enables to simulate crack propagation in a finite element code without using any numerical technique such as node release. The classical Von Mises constitutive relations are modified to include a softening term due to damage, that competes with the material hardening of the stress-strain curve. This effect is described on figure 1 where the differences of behaviour law between the elastic-plastic material and the damaged material are shown. More details about this model can be obtained in [6].

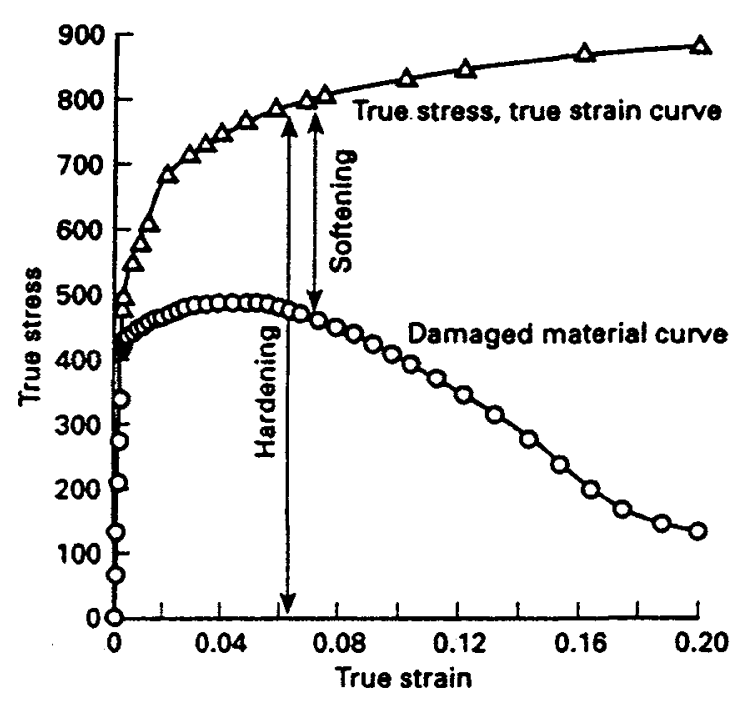

Figure 1 : Stress-strain curve accounting for damage

The model used in this paper refers to the generalised standard material constitutive relations [11], and enables to model material tearing and crack propagation whithout using any numerical technique such as node release. The main advantage of this approach is to assess the crack initiation and growth by using criteria derived from the near crack tip stress and strain fields (local values), which control the material damage. The evolution of the damage is governed by the competition of material hardening and softening. These effects are included in the constitutive relations by modifying the expression of the plastic potential as follows :

$\mathrm{F}=$ Fhardening $+\mathrm{F}_{\text {damage }}=\frac{\sigma_{\varepsilon q}}{\rho}-R(p)+D B(\beta) \exp \left(\frac{\sigma_{m}}{\rho \sigma_{1}}\right)$

where $\quad \sigma_{e q}=\left(\frac{3}{2} \sigma_{i j} \sigma_{i j}\right)^{1 / 2}$

and

$$
\sigma_{m}=\frac{1}{3}\left(\sigma_{k k}\right)
$$


The constitutive relations are derived from $F$, and from the yield criterion $F=0$, through the help of the normality rule. In this expression, $D$ and $\sigma_{1}$ are constants, $p$ is the hardening variable, and $\beta$ the damage variable. Material hardening is assumed to be isotropic, as well as damage. The second term $R(p)$ represents the true stress - true strain curve of the material, and function $B(\beta)$ is equal to :

$$
B(\beta)=\frac{\sigma_{1} \mathrm{f}_{0} \exp \beta}{1-\mathrm{f}_{0}+\mathrm{f}_{0} \exp \beta}
$$

where $f_{0}$ is also a scalar that defines the initial volume fraction of cavities. Material softening caused by cavities growth is taken into account through the third term $F_{\text {damage, }}$ which competes with the hardening part $F_{\text {hardening. }}$

As loading is increasing, the plastification effects make the cavities growing, and damaging the material. When the damage becomes important, softening of the material takes place and the stress strain relation is going down (figure 1). The material resistance becomes lower and lower, until the failure occurs.

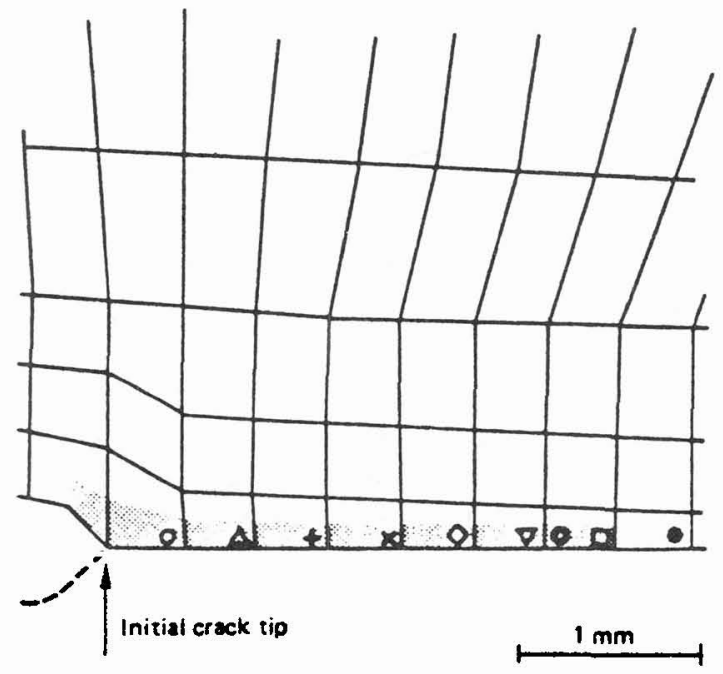

(a)

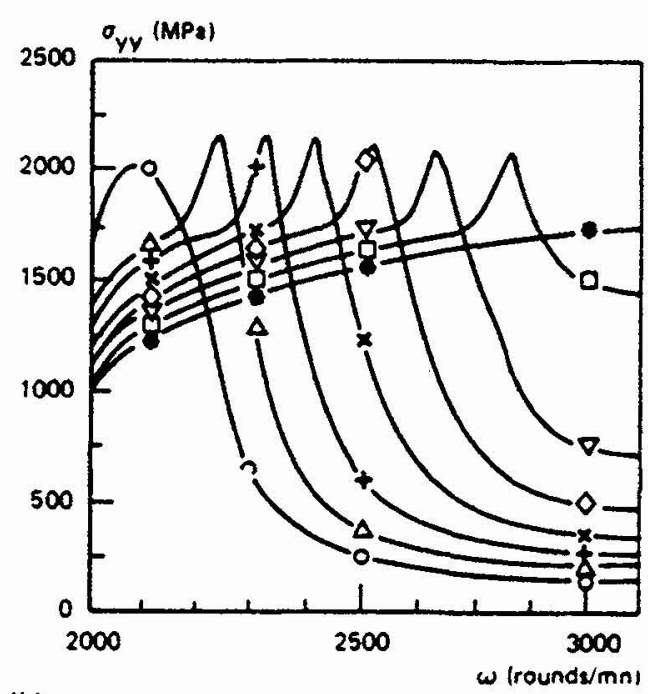

(b)

Figure 2: a) Stable crack growth modelling (damaged zone in grey), and b) evolution of opening stress at the crack tip (the symbols correspond to the location in a))

From the calculation results, we can determine the instants at which the crack growth initiates, as well as the position of the crack tip during the propagation when the opening stress reach a maximum just before collapsing (figure 2). The first maximum observed defines the crack initiation, the second one occurs when the first element fails, the third maximum defines the failure of the second element, an so on... [6].

Then, combining numerical results and J-contour integral calculation provides a numerical J-R curve characteristic of the structure behaviour regarding to ductile tearing. 
Using Rousselier's model, one needs to identify the three parameters that control the fracture behaviour :

- the cavities initial volume fraction $\mathrm{f}_{0}$,

- the metallic matrix stiffness $\sigma_{1}$,

- and the characteristic length $\mathrm{Ic}$ of the finite elements.

Usually, $\mathrm{f}_{0}$ is estimated from the chemical composition of the material [6]. In fact, manganese sulfides inclusions play an essential role in the cavities growth and we can directly relate the initial volume fraction of cavities $f_{v}$ with the percentage of $M n$ and $S$ elements through the Franklin's formula :

$$
\mathrm{f}_{0}=\mathrm{f}_{\mathrm{v}}=0.054(\mathrm{~S} \%-0.001 / \mathrm{Mn} \%)
$$

The second parameter $\sigma_{1}$ may be estimated from the flow stress value but this gives a poor evaluation of it. In practice, mechanical testing is necessary to calibrate $\sigma_{1}$ [7]. The basic specimens used for it are axisymmetric notched tension specimens, for which the calibration procedure is being to be standardised [12].

However, we couldn't follow the same procedure in this study, because we got neither coupons of material in which machining the notched specimens, nor experimental results (provided from axisymmetrcal notched specimen tension tests) to be compared to numerical computations.

Thus, calibration was made with help of results provided from Compact Tension specimens, and the model's parameters were determined so that calculated J-R curve (determined from CT specimen test simulation) fit the experimental one.

\subsection{Presentation of Beremin statistical model}

The BEREMIN model assumes that plasticity is necessary to get cleavage fracture. Whithout any plastic deformation at a microscopical scale, no cleavage microcracks can appear in the material. This condition provides a lower bound threshold below which no fracture event can be obtained. Moreover, this model evaluates the crack tip region loading through the computation of an effective cleavage stress, called the Weibull stress $\sigma_{w}$. Its expression is :

$\sigma_{\mathrm{w}}{ }^{\mathrm{m}}=\int_{\mathrm{V}_{\mathrm{pz}}} \sigma_{1}^{\mathrm{m}} \mathrm{dV} \mathrm{Pz}$

where $\mathrm{V}_{\mathrm{PZ}}$ is the volume of the plastified material zone, and $\sigma_{\mathrm{I}}$ is the maximum prinicpal stress in the volume element $d V_{\mathrm{Pz}}$. This $\mathrm{Weibull}$ stress is computed by integration over the plastic zone, and is related to the structural failure probability by the expression :

$\operatorname{Pr}=1-\exp \left[-\left(\sigma_{\mathrm{w}} / \sigma_{\mathrm{u}}\right)^{\mathrm{m}}\right]$

where $\sigma_{u}$ has the same unit than a stress $(\mathrm{MPa})$, and can be roughly considered as an intrinsic resistance of the material to cleavage fracture. The last parameter $m$ is the Weibull shape parameter that characterises the material resistance scatter. This model includes directly volume or size effects on material or structure resistance to cleavage, through the calculation of the Weibull stress, which is indicating the level of crack tip loading. The crack tip stress and strain fields are evaluated via a finite element analysis of the cracked 
body, and $\sigma_{w}$ as well as $\operatorname{Pr}$ are then calculated by a post-processing routine. Therefore, the above integral that gives $\sigma_{\mathrm{w}}$ is approximated by:

$\sigma_{w}=\left[\sum_{j} \sigma_{I_{j}}{ }^{m}\left(V_{j} / V_{0}\right)\right]^{1 / m}$,

where $\sigma_{\mathrm{lj}}$ is the value of the maximum principal stress in the $\mathrm{j}$ th element plastified, and $V_{\mathrm{j}}$ is its volume. $V_{0}$ is a characteristic cell volume, characteristic of the material itself, and represents a characteristic volume of material that contains enough microcracks to be statistically representative. In practise, this volume can be related with the grain size.

Then, using the two models in a coupled approach is rather simple due to the different kind of numerical implementation they require. The Weibull's model is a post-processor that can be used after a finite element computation with the damage model. So, a two-step finite element gives :

- the amount of stable crack growth expectable during the toughness test or the experiment. This stable crack propagation is derived from the damage model computation,

- the corresponding probability of cleavage occurrence is calculated by the post-processor at any time of the previous computation.

All the results drawn from this coupled approach can be gathered on the same figure, as shown on figure 3.

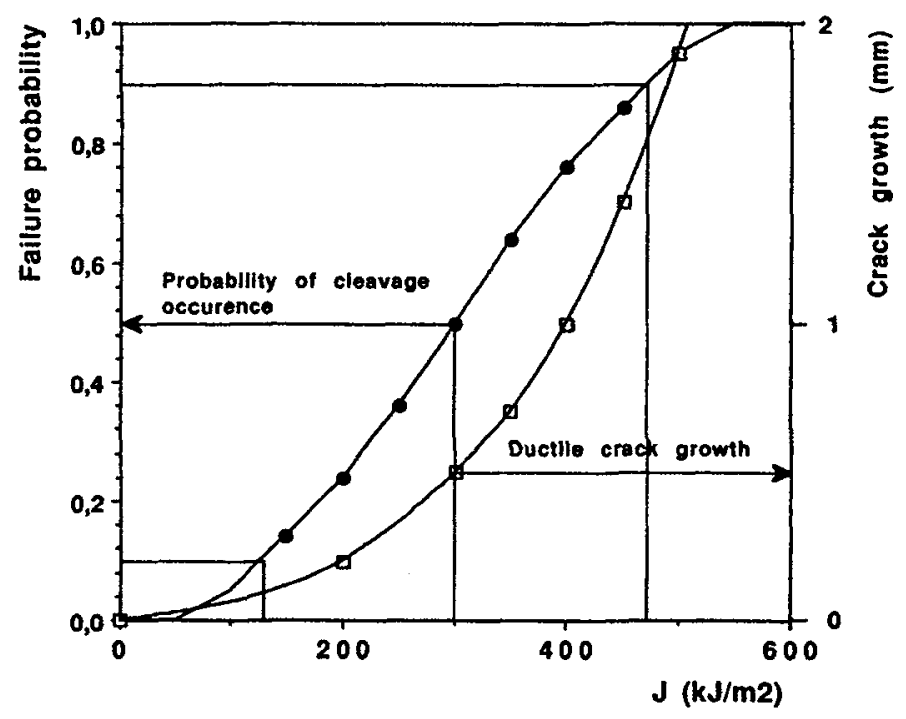

Figure 3 : Cleavage Failure Probability and ductile crack growth evolutions versus J

(Predictions of the model) 


\section{EXPERIMENTAL VALIDATION OF THE MODEL}

The experimental validation of the model has been achieved by analysing toughness tests performed by AEA Technology for a pressure vessel steel (A 533 Grade B) in the transition regime. This important database (about 250 SENB tests covering temperatures from $-120^{\circ} \mathrm{C}$ up to room temperature, and including 10 to $230 \mathrm{~mm}$ thick specimens) has evidenced the specimen thickness effects on toughness properties of the material, as well as influence of prior ductile crack growth on the onset of cleavage fracture.

The predictions of the size effect that are provided by the model are illustrated on figure 4 . It can be noticed that the global shape of the predicted transition curves $K_{t c}=f(T)$ is in good agreement with the design curve retained in both ASME and RCCM code. The size effect predicted by the model shows that the calculated transition curves, for every specimen thickness, produces higher toughness properties than those drawn from the design curve. Although the design curve proved to be conservative, it is shown that the safety margins are decreasing when the specimen thickness is increasing.

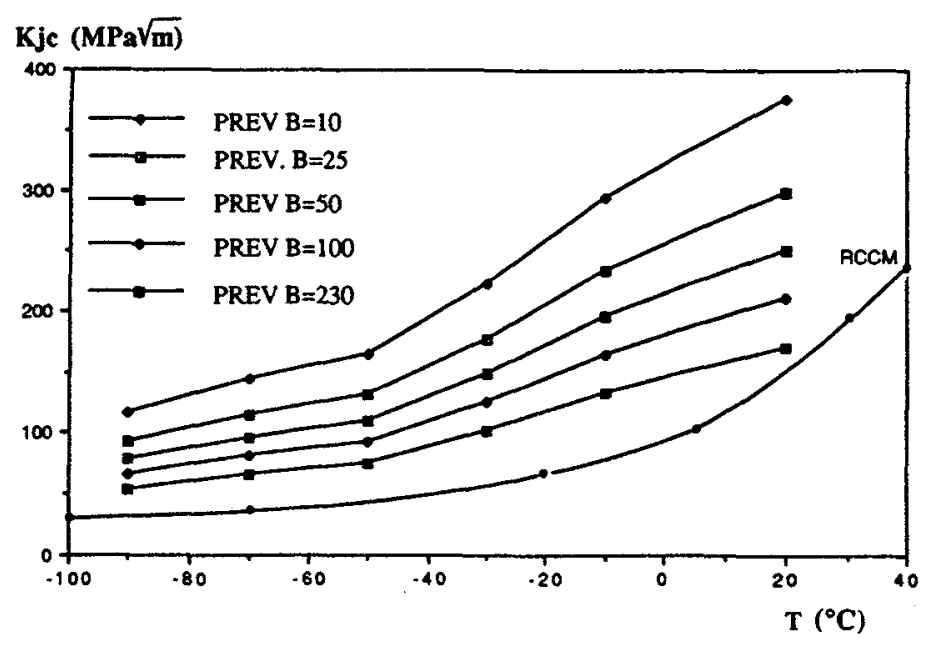

Figure 4 : Comparison of predicted transition curves with the ASME (RCC-M) design curve

The comparison between the predicted transition curve and the experimental results is presented on figure 5 , for $25 \mathrm{~mm}$ thick SENB tests. It can be seen that the predicted lower bound is in good agreement with the toughness test results. Moreover, the benefit of coupling the damage model and the statistical cleavage model is directly evidenced on figure 5 . The predictions of the coupled model are closer to the experimental results than those predicted by the Weibull statistical model alone. The damage effect on mechanical properties of the material and the simulated stable crack growth improve the material resistance to cleavage. 


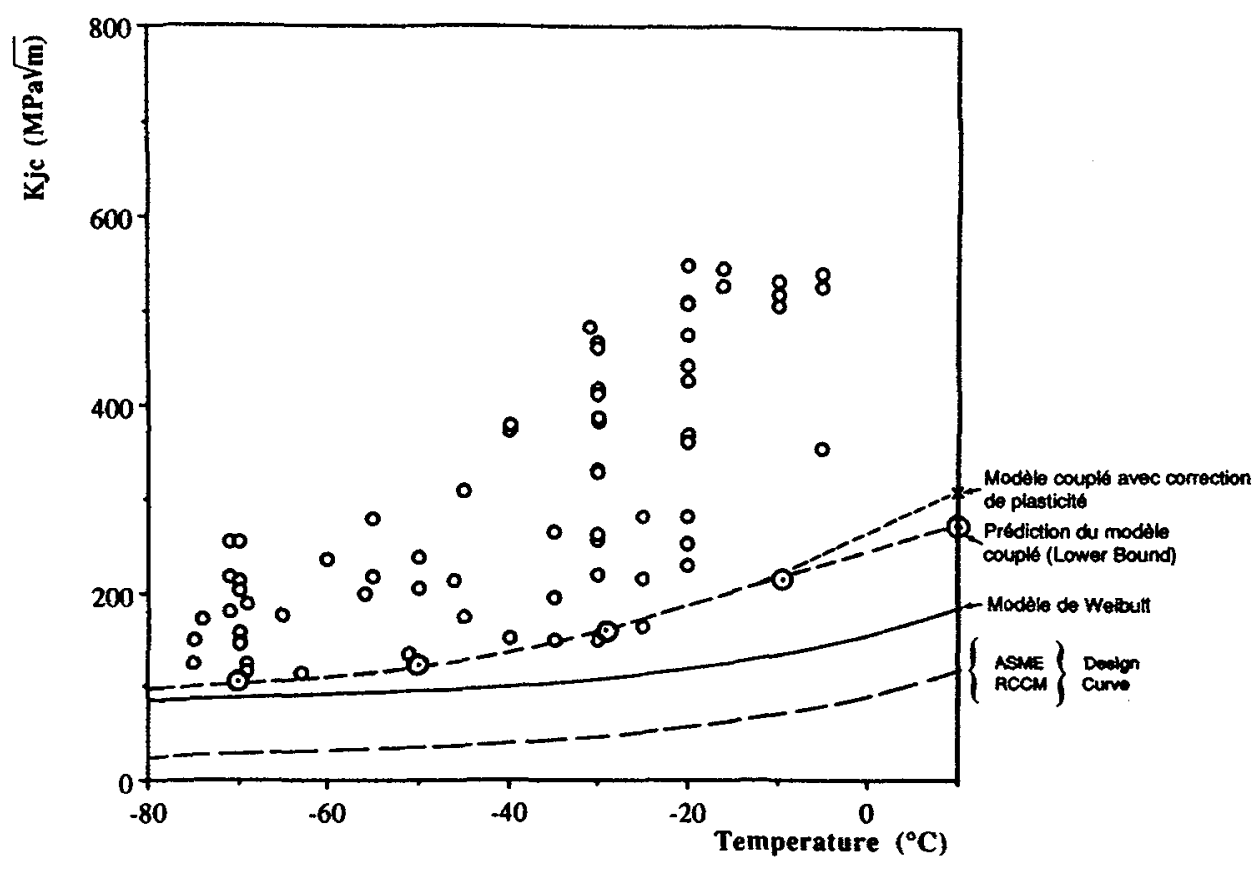

Figure 5 : Comparison of experimental results with predictions of the model

\section{CONCLUSION}

It has been shown that the predictions of the coupled model agree well with the experimental data in the lower and middle transition temperature regime, both in terms of fracture toughness at cleavage instability and the amount of pre-cleavage tearing. It is possible to predict, by this coupled approach, safe lower bound transition curves for a temperature range up to RTNDT $+50^{\circ} \mathrm{C}$. Those predicted curves have also been compared to the ASME design curve, and substantial safety margins have been exhibited. The margins are greater for thin specimens $(10 \mathrm{~mm})$ than for thicker specimens $(230 \mathrm{~mm})$.

\section{References}

[1] Beremin F.M., «A local criterion for cleavage fracture of a nuclear pressure vessel steel», Metallurgical Transaction, Volume 14 A, 1983, pp. 2277-2287.

[2] Wallin K., "The effect of ligament size on cleavage fracture toughness », Engineering Fracture Mechanics, vol.32, 1989, PP. 449-457.

[3] European Group on Fracture Draft procedure for determining toughness in the brittle-to-ductile transition regime. 
[4] Iwadate T. et al., «An analysis of elastic-plastic fracture toughness behaviour for J1c measurement in the transition regime $»$ ASTM STP 803, 1983, pp. 531-561.

[5] Eripret C. et al., « The transition regime modeled by local approach to fracture », ASME AMD Vol. 137, 1992, pp. 195-201.

[6] Rousselier G., «A methodology for ductile fracture analysis based on damage mechanics : an illustration of local approach to fracture », ASTM STP 995, 1989, pp. 332-354.

[7] Eripret C. and Rousselier G., «First Spinning Cylinder Test analysis using a local approach to fracture », Nuclear Engineering and Design 152 (1994), pp. 11-18.

[8] Lidbury D.P.G. et al., « Prediction of the First Spinning Cylinder Test using continuum damage mechanics », Nuclear Engineering and Design 152 (1994), pp. 1-10.

[9] Bethmont et al., «A methodology for ductile fracture analysis based on local approach to fracture : application to the NKS-3 thermal shock experiment », 15th MPA Seminar, Stuttgart, 5-6 October 1989.

[10] Schmitt W. and Blauel J.G., «Recent Development in the application of Micromechanical models for thje Evaluation of the Fracture Toughness of PWR components », ASTM Symposium on Small specimen Test Techniques and their application to Nuclear Reactor Vessel Thermal annealing and Plant Life Extension, New Orleans, January 29-31 1992.

[11] Rousselier G., «Finite deformation constitutive relations including ductile fracture damage » in Three Dimensional Constitutive relations and Ductile Fracture, North Holland, Amsterdam, 1981.

[12] Draft Procedure to measure and calculate Local Fracture Criteria on Notched Tensile Specimens, ESIS / P6-94 D. 